\title{
Observações sobre a educação escolar indígena e saberes tradicionais Guarani e Kaiowá em Dourados, Mato Grosso do Sul: múltiplas veredas, diferentes perspectivas
}

\section{Comments on indigenous school education and traditional knowledge Guarani and Kaiowá at Dourados, Mato Grosso do Sul: multiple walls, different perspectives}

Rosalvo Ivarra Ortiz ${ }^{1}$

DOI

10.30612/re-ufgd.v6i12.9563

Recebido em 12/03/2019 - Aceito em 04/12/2019

Resumo: Torna-se evidente que a compreensão de um universo de relações sociais indígenas por meio da análise da pratica de rituais religiosos, nos remete a pensar não apenas em uma direção e sim em uma pluralidade de sentidos, signos, símbolos e conceitos que estão em constante suspensão e que referem a própria experiência vivida representada em sua execução; sistemas são construídos e junções entre saberes são necessárias para perpetuação de tradições e conhecimentos, e neste universo de construções e dinamicidades onde vários atores participam no sentido de conectar sentidos, experiências, praticas, que se constituirão em modelos a serem seguidos pelas futuras gerações, a educação se faz presente como uma necessidade de se fazer sentir e se fazer ser social e pertencer a coletividade e para esta contribuir para sua existência. Nesta acepção, conseguimos perceber o ritual como uma espécie de linguagem coletiva, um símbolo representativo de algumas verdades transcendentais, que incorporam uma pratica dinamizada que permeia por uma rede complexa de ações significativas capazes de unir um grupo e convencê-lo por meio de sua eficácia (MAUSS, 2003). Mais do que um movimento cosmológico de ordem reflexiva e ou contemplativa, "os rituais de uma sociedade ampliam, focalizam, põem em relevo e justificam o que já é usual nela" (PEIRANO, 2002, p. 8).

Palavras-chave: Guarani e Kaiowá, Educação, Cosmologia.

Abstract: The understanding of a universe of indigenous social relations through the analysis of the practice of religious rituals, leads us to think not only in a direction but in a plurality of senses, signs, symbols and concepts that are in constant suspension and that they refer to the lived experience represented in its execution; systems are built and junctions between knowledge are necessary for the perpetuation of traditions and knowledge, and in this universe of constructions and dynamicities where several actors participate in the sense of connecting senses, experiences, practices, that will constitute models to be followed by future generations, the education is present as a need to make oneself feel and to become social and belong to the community and to contribute to its existence. In this sense, we can perceive ritual as a sort of collective language, a symbol representative of some transcendental truths that incorporate a dynamized practice that permeates through a complex network of meaningful actions capable of uniting a group and convincing it through its effectiveness (MAUSS, 2003). More than a cosmological movement of a reflexive or

\footnotetext{
1 Possui graduação em Ciências Sociais (Licenciatura Plena) pela Faculdade de Ciências Humanas da Universidade Federal da Grande Dourados- (FCH/UFGD). Atualmente é Mestrando em Geografia Humana pela Faculdade de Filosofia, Letras e Ciências Humanas da Universidade de São Paulo- (PPGH/FFLC/USP). E-mail: rosalvortiz@hotmail.com
} 


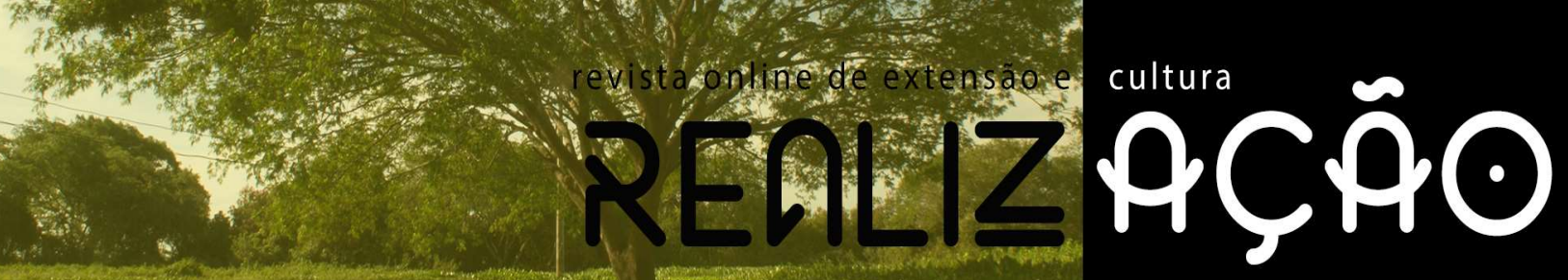

contemplative order, "the rituals of a society enlarge, focus, highlight and justify what is already usual in it” (PEIRANO, 2002, p. 8).

Keywords: Guarani and Kaiowá, Education, Cosmology.

Cayua de $\mathrm{Caa}=$ mato e Awa $=$ Homem. Encontramos na literatura em todas as grafias possíveis, como Cayua, Caygua, Caaygua, Cayagua, Cagoa, Cayoa, Caygoa, Cayowa, Caingua, Caa-owa, Cahahyba, Cahuahiva, Cabaiva e Ubayha. Poucos viajantes entraram em contato mais próximo com os ariscos Cayuas. Com o afastamento dos jesuítas... povos inteiros desapareceram, assim deles sabemos pouco mais do que os nomes. Somente nas regiões situadas muito no interior, de acesso difícil, encontramos tribos, que sempre se conservaram separadas dos brancos (...) obedecendo aos seus costumes antigos. O modo hostil e a desconfiança destas hordas contra tudo o que é estranho dificultou muito um estudo profundo do seu modo de viver (KOENIGSWALD, 1908, p. 1-2-3).

Iniciamos esta discussão a dizer que nos rituais religiosos e festivos, como em outros eventos sociais onde se reúnem grandes coletivos, existem conexões e transformações múltiplas e estas estão vinculadas as variadas formas de se pensar a cultura como um sistema de significados que é transmitido e se comunicam historicamente, incorporado por meio de símbolos - sagrados ou não - em um sistema de concepções herdadas e expressas em formas simbólicas por meio das quais os homens e desenvolvem seu conhecimento e suas atividades em relação à vida e a sua práxis. Pensando um viés social de magnitude extensiva, para além de sua simples forma de viver em grupo e se comunicar, esses sujeitos se constituem em atores capazes de dinamizar sua vida individual e coletiva, porém, sempre necessitando de elementos capazes de entrelaçar seu sentimento aos do grupo social do qual está inserido.

[...] O homem tem uma dependência tão grande em relação aos símbolos e sistemas simbólicos a ponto de serem eles decisivos para sua viabilidade como criatura e, em função disso, sua sensibilidade à indicação até mesmo mais remota de que eles são capazes de enfrentar um ou outro aspecto da experiência provoca nele a mais grave ansiedade sendo assim (grifo nosso) [...] os símbolos religiosos oferecem uma garantia cósmica não apenas para sua capacidade de compreender o mundo, mas também para que, compreendendo-o, dêem precisão a seu sentimento, uma definição às suas emoções que lhes permita suportá-lo, soturna ou alegremente, implacável ou cavalheirescamente. (GEERTZ, 1989, p. 73-77).

Partindo dos pressupostos iniciais, pensar em analisar conexões e intercomunicações em uma dimensão dual que externa a experiência de coabitar em mundos e lógicas totalmente díspares e pensar como essas relações, interações e inter-relacionamentos transcorrem distintamente e simultaneamente em nossa vida social, problematizando imaginários cosmológicos dos Kaiowá, 
realização do presente trabalho, apresentar apontamentos sobre a Educação Escolar Indígena principalmente no tocante aos saberes místicos- tradicionais e discutir o ritual Avat ikyry, um significativo ritual realizado pelos índios Kaiowá habitantes da Aldeia de Panambizinho, distrito de Panambi, localizada no município de Dourados, Estado do Mato Grosso do Sul, região CentroOeste do Brasil com a finalidade futura, de construir uma etnografia desse ritual: seus imaginários, simbologias e práticas.

O povo Guarani e Kaiowá possui muitos místicos-conhecimentos que orientam sua organização social, dos quais são transmitidos há outras gerações por meio das histórias orais, memorísticas e cantadas. Por assim dizer, o canto exerce importância primaz para sua existência e para a perpetuação de suas tradições, além de garantir a reprodução cultural de sua sociedade. Este é ensinado desde a maturidade e realizado para que seja propagado e não haja o fim terreno do povo. Outro elemento importante para entender a organização social Kaiowá e conectar ao processo educacional familiar são os princípios cosmológicos, pois estes se constituem como fator essencial para se compreender a gênese e a própria concepção de existência do povo Tupi-Guarani.

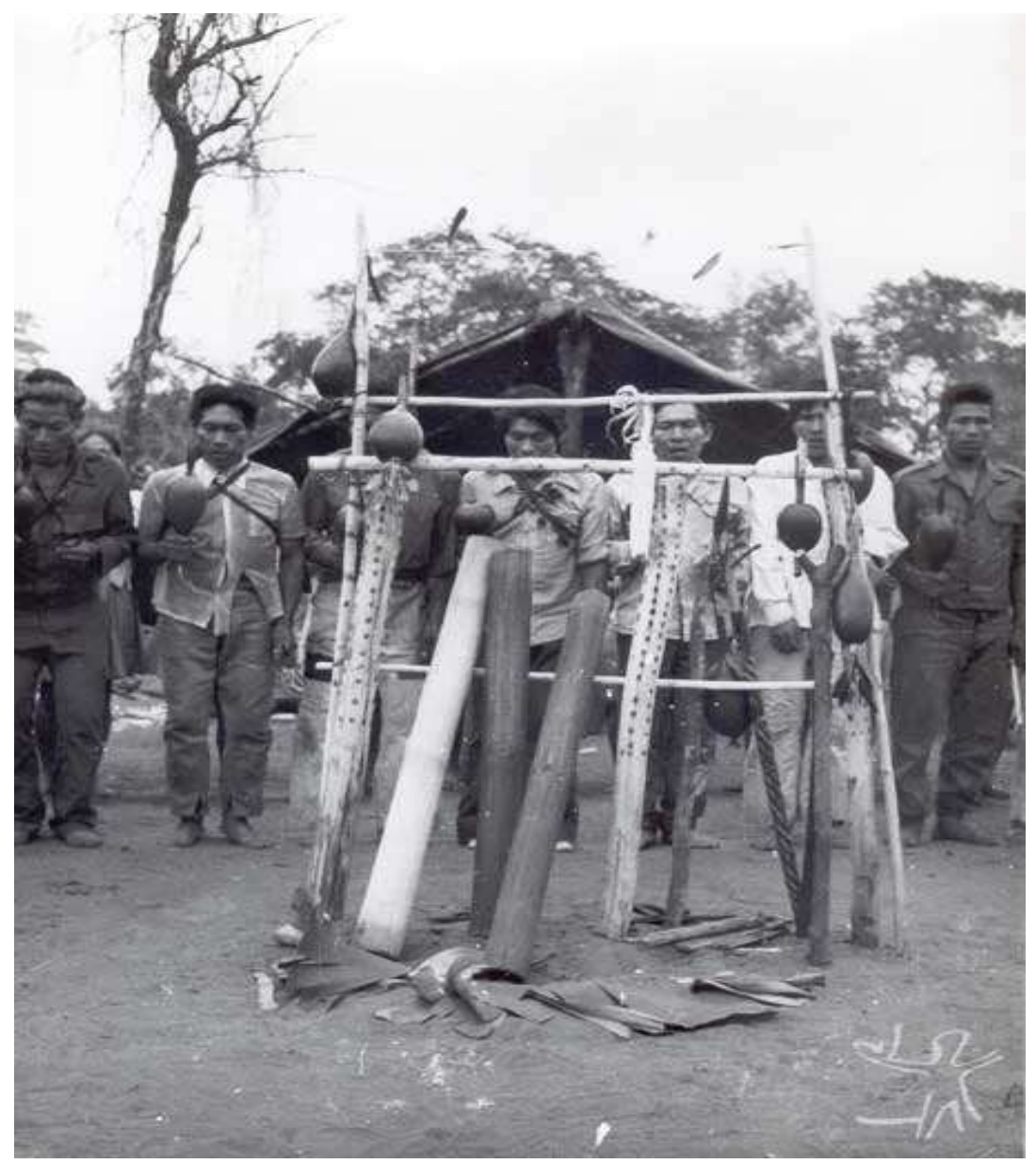


Figura 2. Festa Avati Kyry seguido de canto ritualístico. Foto: Egon Shaden, 1949. Disponível em: https://pib.socioambiental.org/pt/Povo:Guarani_Kaiow\%C3\%A1

Mais do que uma ação religioso-ritualística, a festa do milho novo condiz em um momento de congraçamento e união entre os povos indígenas e membros convidados e uma maneira de apresentar uma cultura de re-existência aos modelos impostos pela sociedade não indígena, sobretudo as políticas colonialistas de extermínio, etnocídio e necropolítica (MBEMBE, 2003). De outro modo Geertz (1989, p. 83) nos diz que "podemos chamar essas cerimônias totais de "realizações culturais" e observar que elas representam não apenas o ponto no qual os aspectos deposicionais e conceptuais da vida cosmológica convergem para o crente, mas também o ponto no qual pode ser melhor examinada pelo observador a interação entre eles."

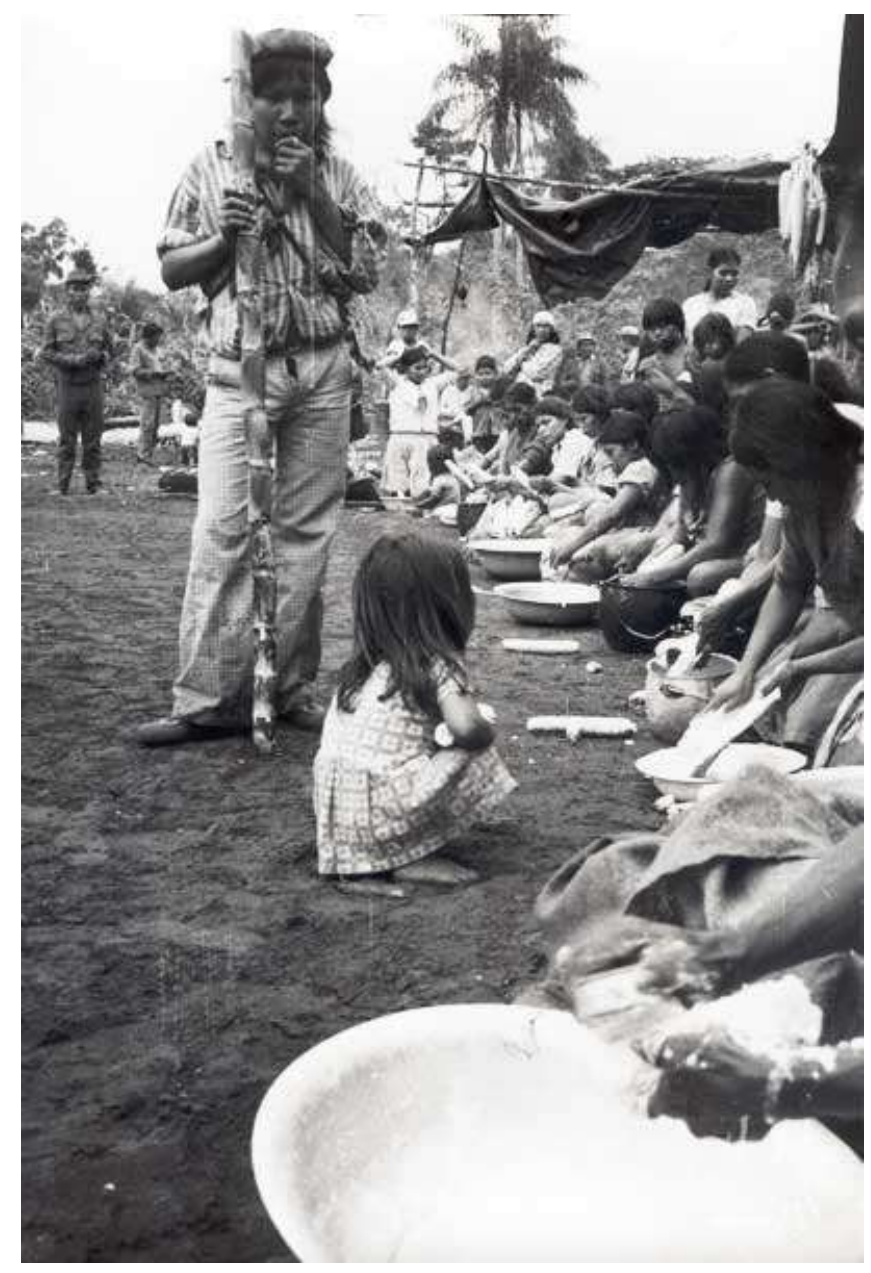

Figura 3. Festa Avati Kyry no interior do Tekohá Kaiowá. Foto: Egon Shaden, 1949. Disponivel em: https://pib.socioambiental.org/pt/Povo:Guarani_Kaiow\%C3\%A1

No desenvolvimento deste trabalho, com a construção da etnografia, temos a pretensão de problematizar alguns aspectos como: 1). a complementaridade do território ritualístico, 
pensando além de seus limites; 2). as relações sociais construídas dentro e fora do Tekohá; 3). o solo como elemento complementar sagrado do corpo, da alma, do espírito e a importância do milho para o grupo; 4). substância corporal e espiritual e como é vista essa relação do homem (índio e não índio) com a natureza; 5). sobre a importância da manutenção da linguagem materna, simbólica e ritual, entre outras. A corporalidade como idioma simbólico, noções sobre construção da pessoa e da identidade Guarani e Kaiowá, complexos de cura e adoecimento e como a deturpação do entendimento das práticas ritualísticas podem atribuir significações na sua vida cotidiana e contribuir para o desequilíbrio. Perceber e interpretar a questão da violência externa e interna (em relação à terra, o milho e ao povo Guarani e Kaiowá) e realizar uma possível conexão ao ritual. Utilização de artefatos rituais e quais as possíveis ligações destes artefatos com a atividade humana. $\mathrm{O}$ que os indígenas entendem sobre o ritual e qual a sua importância de sua realização para a sociedade Guarani e Kaiowá; o que os motiva em realizar tal ação? Nesse sentido, também procuro explorar a visão indígena sobre o sistema de saberes tradicionais e práticas rituais e como essas são passadas a novas gerações, tentando problematizar esse movimento de formação e incorporação de conhecimentos inerentes à prática dos rituais, frente a esse contexto de mudanças verificados nas últimas décadas.

Defende-se aqui também o pensamento do pensador alemão Max Weber apresentado por Geertz na obra a Interpretação das culturas, que classifica o ser humano como "um animal amarrado a teias de significados que ele mesmo teceu”. Dessa maneira, acredita-se assim que os elementos interligados que formam os rituais praticados pelos Guarani e Kaiowá transferem uma complexidade de sentidos e simbolizam toda uma forma de fazer específica, própria, identificando o grupo e dessa maneira, amplia-se a necessidade do cuidado à sua manutenção e perpetuação e que a Educação escolar indígena - no tocante a preservação do patrimônio material e imaterial - faz parte desse processo, seja ela a partir dos mitos e rezas contadas e realizadas por rezadores ou até mesmo por pessoas da comunidade que passam seus conhecimentos no seu cotidiano, pela sua prática e experiências vividas.

No que se refere a noção de identidade, Chamorro (2015, p. 237) nos indica que esta não é recebida por herança em que as gerações novas recém das gerações mais velhas para, por sua vez, passar as mãos de outras gerações; e tão pouco é uma construção a bel-prazer. "Ela se constrói na conjuntura histórica do presente e a partir de predisposições e referências herdadas, que também resultaram de situações históricas. Nesse sentido, o que os Kaiowa apresentam como sua cultura original hoje tem história. É resultado de seu agir histórico. As gerações passadas tiveram que dar 
conta de outros desafios no passado, no âmbito da sua própria cultura e no contato com outros povos. Tiveram que garantir sua sobrevivência em meio a mudanças ambientais, contatos com outros grupos humanos e mudanças que se davam no interior do próprio grupos."

De acordo com a antropóloga Katya Vietta (2001, p. 253) os Kaiowa e Guarani crentes e não crentes - creditam o surgimento de várias doenças como feitiço, nervosismo, violência, suicídio, entre outras, não apenas ao caráter orgânico, físico, mas, também ligados ao desequilíbrio da pessoa e da sociedade, diante de inúmeras mudanças vivenciadas nas últimas décadas, como a quebra de mobilidade e do modo de ser desse povo, como nos indica um dos principais historiadores da cultura Guarani e Kaiowá de Mato Grosso do Sul Antonio Brand (2001, p. 259).

Neste contexto, conectando com o conceito da historiadora, linguista e antropóloga paraguaia Cândida Graciela Chamorro (2015, p. 236), quando nos diz que "vista do interior de cada comunidade, porém, a religião tradicional vai perdendo visibilidade para as Igrejas, podendo haver para um rezador e uma rezadora, com certo reconhecimento, uma dezena de pastores ou missionários no local. No nível mais cotidiano, os Kaiowa associam também suas práticas religiosas tradicionais e das Igrejas evangélicas a rituais afro-brasileiros. O trânsito de uma religião para outra é, ao que parece, determinado pela necessidade de resolução de problemas práticos da vida cotidiana, como o consumo excessivo de bebidas alcóolicas, desentendimentos e principalmente problemas de saúde, a maioria dos quais associados a práticas de feitiçaria.”, podemos apontar para um movimento de ressignificação da prática e experiência religiosa Kaiowá.

Em atenção ao que corrobora Gersem José dos Santos Luciano Baniwa (2006) percebemos que esse processo educacional desenvolvido nas práticas rituais e ampliado pelos mitos e nas tradições orais passadas pelas gerações anteriores é fundamental para a transmissão e produção dos conhecimentos tradicionais indígenas além de se constituir em um importante instrumento de fortalecimento de culturas e das identidades individuais e coletivas. Sendo também um forte elemento constituinte para o estabelecimento de direitos e busca por outros não conquistados ainda.

Ainda segundo esse autor, os saberes ancestrais são transmitidos oralmente e em uma práxis que se renova constantemente e assim sendo, constitui-se em um poderoso meio de resistência (interna e externa): também pela observação, experiência, autorreflexão transmitida pelas histórias contadas pelos mais velhos por meio dos mitos e ou transmitidos nos rituais, histórias, festas e outras cerimônias e eventos como o da pesca comunitária. 
No tocante a este último evento citado tive a oportunidade de presenciar/vivenciar uma pesca comunitária realizada na aldeia em que frequento e, que segundo o "Seu Valdomiro" (liderança Kaiowá em Panambizinho), teria sido a primeira naqueles moldes. Vários ensinamentos dos quais tinha obtido apenas nas leituras em sala e em casa pude constatar em loco com a observação deste significativo evento.

Em de dezembro de 2018, na aldeia de Panambizinho, ocorreu uma pesca comunitária onde houve a participação da comunidade local e de outras não residentes ali; foi percebido que havia alguns intelectuais indígenas e não indígenas participando ativamente do evento: uma grande reunião de pessoas das quais, se espalhavam pelo espaço em tarefas distintas e não eletivas. Eram jovens, crianças, adultos, idosos, mulheres, todos em prol do mesmo objetivo e em consonância para o coletivo. Muitos estavam no rio para apanharem os peixes em uma imensa rede carregada por inúmeros braços e vozes, enquanto que outros ficaram do lado de fora para ajudar na recepção e distribuição do alimento às famílias que aguardavam pacientemente e organizadamente em uma fila. Abundantemente os peixes chegavam em cestos e sacos utilizados para fins da agricultura e lançados em uma caixa d'água de fibra controlada pela "Dona Roseli", esposa do Seu Valdomiro. Ninguém passava por ali sem ser atendido e na hora da entrega, diálogos eram realizados - em língua nativa e em português - em um movimento repetitivo entre os presentes. Podemos perceber como a felicidade pairava no local e esta não era apenas pelo recebimento de algo para o corpo, mas, algo além era festejado e incorporado a alma: a união e compartilhamento de um mesmo sentimento de participarem do mesmo grupo e partilharem da mesma alegria, sonho e esperança.

Pensando em uma concepção direcionada a cultura, entendo que o que faz o pesquisador procurar encontrar respostas estudando as culturas - como o que estou tentando fazer com as minhas idas em Panambizinho - está no cerne de que esta é constituída por um complexo e dinâmico universo de pensamentos e ação singulares que traduzem experiências vividas experimentadas no seio das relações mediatizadas pelos sujeitos históricos e que sem a mediação de um educador - no meu caso os professores e no caso dos Kaiowá a própria comunidade - esse sistema cultural demonstra fragilidade e tende a esmaecer ou até mesmo desaparecer.

Ao desenvolver esta investigação temos como um dos ensejos principais o de apreender, compreender e a posteriori interpretar novas experiências relativas ao trabalho de campo principalmente no tocante a prática exercida pelos intelectuais indígenas em seus trabalhos de pesquisa e como estes conseguiam se inserir no meio da comunidade para abordar assuntos tão 
singulares ao modo de viver dos grupos estudados.

Tendo como base o contato com as etnografias e trabalhos de campo dos clássicos como Lévi-Strauss, Geertz, Malinowski, Roy Wagner, entre outros, notamos o quão pode parecer, e de algum modo, se tornar complicada a relação entre pesquisador e nativo e a construção da etnografia perante as diferenças de lógicas e modos de viver e de pensar, aliados a prática descompassada do pesquisador com seu objeto de estudo; com o passar do tempo e com o aprofundamento de leituras, unido ao manuseio dos trabalhos desenvolvidos pelos intelectuais indígenas e as trocas de conhecimento em sala, o que tomava como problema, começava a florescer em uma concreta possibilidade de meu trabalho se realizar de uma maneira mais simples e mais próxima do que pensava quando realizei meu primeiro projeto de pesquisa. O que mais nos afligia era no tocante ao contato e como realizar nossa inserção na comunidade: portanto, a priori, discutir assuntos dos quais ainda não era presente em nosso cotidiano e não faziam parte de nossa experiência de vida.

Com o transcorrer dos diálogos e problematizações dos textos, algo além foi se construindo ao compreender mais intimamente a proposta elencada e algumas questões surgiram: poderia vincular meu trabalho às práticas escolares nas aldeias e as discussões propostas pelos intelectuais indígenas relacionadas aos projetos curriculares diferenciados e a fortificação da educação escolar indígena? (Devemos dizer que entendemos que esta temática-foco central circula em todos os textos lidos e nas questões levantadas pelos intelectuais indígenas e não indígenas e pelos colegas em sala de aula).

Outras questões em que foram pensadas neste período em sala e que com certeza podem auxiliar-nos na pesquisa futura: 1). O universo da educação escolar indígena poderia me auxiliar em minha pesquisa? Em que sentido: Como realizar esse interposto entre Educação Escolar Indígena e a prática ritualística dos Guarani e Kaiowá em Panambizinho? 2). Como evidenciar a relação entre os conhecimentos tradicionais disseminados e transmitidos entre os rezadores e os indígenas de mais idade aos mais novos? 3). Como perceber esse movimento como resistência nos dias de hoje? Finalizamos a dizer que percebemos por meio do estudo, os conhecimentos tradicionais dos Guarani e Kaiowá, questionar a que ponto esta ligação é verdadeira e eficaz, existente, capaz de interligar pensamentos e povos em suas tradições e conhecimentos e para além desse movimento, capaz de uni-los em uma mesma dimensão social. Portanto, torna-se evidente que esse processo ritualístico é histórico (como podemos observar nas fotografias de Egon Schaden1974) e sempre fez parte da cosmologia Guarani Kaiowá. 
A partir dos postulados anteriores, é importante ressaltar que o trabalho antropológico a envolver povos indígenas, sobretudo, no estado de Mato Grosso do Sul e principalmente com os Guarani e Kaiowá é claramente inconveniente pelo Estado brasileiro, "bancadas ruralistas" no Congresso Nacional, representantes dos "ruralistas" de forma impertinente. Tudo isso vem a ocasionar em perseguições, ameaças, processos administrativos, processos criminais a gerar uma grande instabilidade, desequilíbrio e insegurança profissional e pessoal. É aqui cabe destacar a ameaça sofrida em 2017 pelo antropólogo Levi Marques Pereira, onde segundo o mesmo- um carro estranho estava a rondar sua residência, uma tentativa explícita de intimidação e cerceamento. É na conjuntura atual toda essa situação fica ainda mais comprometida, onde fica evidente a sua real intenção. É tudo isso afeta (FAVRET-SAADA, 2005) gravemente o modo de se fazer etnografias, mas produz engajamento.

Ainda nesse sentido, fica claro o preconceito vivenciados pelos Guarani e Kaiowá e, isso também se estende a nós pesquisadores/as, onde somos constantemente visualizados com desconfianças e reprovação pelo chamado Karai Kuera (senhor fazendeiro ou simplesmente nãoindígenas), sobretudo, por estamos imersos nesse contexto de violências, mas é fundamental mencionar que nesse doloridos processos somos pactuados e pacificados no conviver Guarani e Kaiowá.

É de grande relevância ressaltar que o estado de Mato Grosso do Sul, tem sem mostrado um campo fértil para estudo antropológico, histórico, geográfico, linguístico a envolver os povos indígenas. Nesse processo muitos indígenas tem escolhidos a Antropologia para contribuir com outro olhar sobre sua própria cultura- a levantar novas possibilidades e a renovar a teoria e o formular antropológico e, isso não rebaixam os trabalhos dos não-indígenas, muito pelo contrárioacrescenta ainda mais essa dinâmica. Por assim dizer, Scott (1999) é aquilo que nos institui, altera as práticas cotidianas e transformam quaisquer teorias ou metodologias.

No final também vale apenas destacar a importância da educação escolar indígena desenvolvida na Universidade Federal da Grande Dourados através da Faculdade Intercultural indígena Tekó-Arandú, onde muitos estudantes são oriundos de áreas de retomadas regularizadas ou ainda em áreas de litígios. Muitos desses acadêmicos estão a pensar no sentido de ressignificar a sua cosmologia- a trazer novos elementos- a confrontar ideologias/pensares/viveres dos indígenas com não-indígenas. Assim a autobiografia tem sido um novo instrumento de pesquisa, onde os indígenas narram suas próprias histórias em detalhes, onde estão as aflições, inquietações, futuros das comunidades, etc. 
Dessa forma, é possível dizer que reflexionar sobre a etnografia/trabalho de campo, sobretudo no fazer antropológico/etnológico nos propicia olhar para nossa conduta mediante a esse processo e, principalmente visualizar e perceber como as novas diretrizes e dinâmicas etnográficas é moldada pela nossa história e memória, nossa cultura, nossa sociedade, nossa cor, nossa raça, nossa sexualidade, nossas escolhas, nossas condutas, nossas lutas, nossas resistências. Outro leque de possibilidade é refletir sobre os principais risco, insegurança e instabilidade- a atingir todas as partes que envolvem o observador/observado e pesquisador/interlocutor. Dessa forma, fica claro que não há uma receita pronta para se fazer uma pesquisa antropológica- os caminhos são tortuosos, cheias de idas e voltas, mas a persistência é um bom caminho a ser seguimo-lo a procurar- inovar, ressignificar, repensar, refazer, ressurgir, rememorar, reviver. Assim poderíamos dizer que há uma metodologia das resistências- única, própria, diferenciada e histórica.

Portanto, no limiar deste artigo (in)concluso, compreendemos que é praticamente improvável nutrificar uma metodologia entre os Guarani e Kaiowá, sobretudo, em Dourados- Mato Grosso do Sul perante a grave conjuntura de violação aos direitos humanos a que esses povos estão subjugados há muito tempo, mas sobretudo, nos últimos anos, onde vidas são ceifados de formas trágicas sem nenhuns escrúpulos. Em nossa investigação, constatamos diversas maneiras de (re)existências impulsionadas pelo agronegócio frente aos direitos às vidas, onde deparamos com um rico proprietário de terra- o chamado "ruralista", a nos dizer a seguinte frase: "cuidado com o que irá escrever, poderá ter consequência”! Isso significa que tornar-se antropólogo em terras de latifundiários é mais do que desafiador, além de portar no olhar as dores, os medos, as aflições, as lutas, as resistências, os sangues, as memórias Guarani e Kaiowá. Por fim, cabe frisar que muitas pesquisas vêm sendo realizados acerca da cultura Guarani e Kaiowá em território sul-matogrossense, dentre os quais mencionamos algumas de nossa autoria (MACHADO, IVARRA ORTIZ, 2018ab; IVARRA ORTIZ; MACHADO, 2019, IVARRA ORTIZ, 2019ab).

\section{Referências}

BANIWA, Gersem dos Santos Luciano. O Índio Brasileiro: o que você precisa saber sobre os povos indígenas no Brasil de hoje - Brasília: Ministério da Educação, Secretaria de Educação Continuada, Alfabetização e Diversidade; LACED/Museu Nacional, 2006.

CHAMORRO, Graciela. História Kaiowa: das origens aos desafios contemporâneos. São Bernardo do Campo: Ñhanduti Editora, 2015.

Terra madura, yvy araguyje: fundamento da palavra guarani. Dourados: UFGD editora, 2008. 
$342 \mathrm{p}$.

Decir el cuerpo: História y etnografía del cuerpo em los pueblos Guaraní. Assunção: Tiempo de Historia, Fondec, 2009. 408 p.

CAVALCANTE, Thiago Leandro Vieira; GONÇALVES, Carlos Barros. Fronteira e Identidades: Encontros e desencontros entre povos indígenas e missões religiosas. São Bernardo do Campo: Nhanduti Editora, 2011. 352 p.

. Kurusu Ñe'ëngatu: palavras que la historia no podría olvidar. Assunção, Paraguai: Talleres Gráficos de Litocolor, 1995.

FAVRET-SAADA, J. Ser afetado (tradução de Paula de Siqueira Lopes). Cadernos de Campo, n. 13, p. 155-161, 2005.

GEERTZ, Clifford. A interpretação das culturas. Rio de Janeiro: Ed. Guanabara, 1989.

O saber local. Petrópolis: Vozes, 2012.

IVARRA ORTIZ, R. Múltiplos olhares sobre os Guarani de Mato Grosso do Sul: história, organização social, arte e cosmologia. Articulando e Construindo Saberes, v. 4, 2019. https://doi.org/10.5216/racs.v4i0.59577

Cultura Material e Arte Indígena como Campo de Pesquisa: O caso dos Guarani e Kaiowá de Mato Grosso do Sul. IAÇÁ: Artes da Cena, v. 2, p. 148-168, 2019. DOI: http://dx.doi.org/10.18468/iaca.2019v2n2.p148-168

MACHADO, Almires Martins. Cosmovisão Guarani, Terena e Kaiowá do Território Indígena Jaguapiru e Bororó: coexistência entre eu, tu, nós e os outros agentes da história e da memória. TELLUS (UCDB), v. 19, p. 213-231, 2019.

DOI: http://dx.doi.org/10.20435/tellus.v19i40.618

KOENIGSWALD, Gustav von. Die Coroados im sudlichen Brasilien. Globus, 1908, p. 27-32.

MACHADO; IVARRA ORTIZ. Mbaraka Ju: arte, memoria y habla sagrada Guarani. Revista Euroamericana de Antropología, v. 00, p. 73-81, 2018.

IVARRA ORTIZ, R. Tembiasakue Rapê: a longa estrada Guarani na história e na memóriareconstruindo o passado, ressignificando o presente e trilhando o futuro. TELLUS (UCDB), v. 18, p. 189-205, 2018.

DOI: http://dx.doi.org/10.20435/tellus.v18i37.525

MAUSS, Marcel. Sociologia e antropologia. Rio de Janeiro: COSAC NAIFY, 2003.

MBEMBE, Achille. Necropolitics. Public Culture, 15, 2003, p. 11-40.

MELIÁ, Bartomeu. La comprensión guaraní de la vida buena in Nande Reko: La comprensión guaraní de la Vida Buena. La Paz, Bolívia: Editorial Cuatro Hermanos, 2008. p.

PEIRANO, Mariza (org.). O dito e o feito: ensaios de antropologia dos rituais. Rio de Janeiro: Relume Dumará, 2002. 


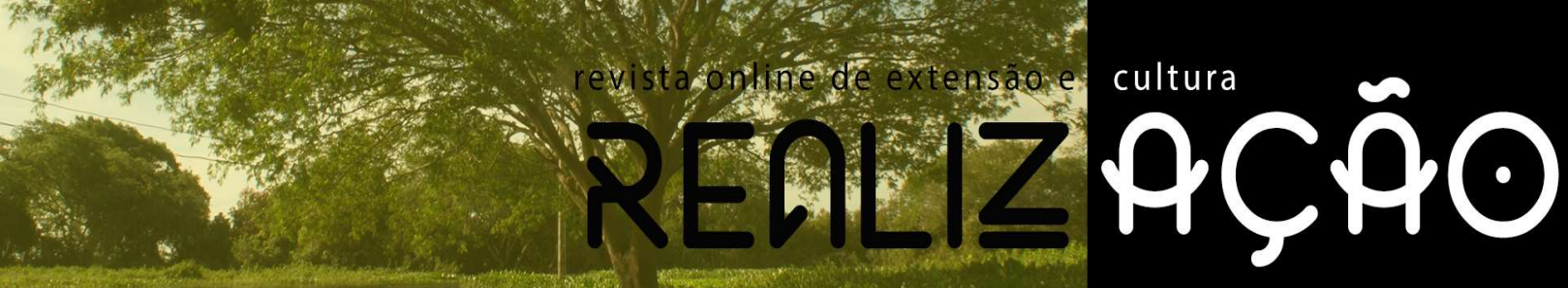

PEREIRA, Levi M. "O pentecostalismo Kaiowá: uma aproximação dos aspectos sociocosmológicos e históricos". In: Wright, Robin (org.) Transformando os Deuses. Vol. II. Campinas, SP: Editora da UNICAMP, 2004.

SAHLINS, M. Ilhas de história. Tradução de Barbara Sette. Rio de Janeiro: Jorge Zahar, 1990. Cultura e Razão Prática. Rio de Janeiro: Jorge Zahar Editor, 2003.

SCHADEN, Egon. Aspectos fundamentais da cultura Guarani. São Paulo: EPU; Edusp, 1974. $208 \mathrm{p}$.

SCOTT, Joan. Experiência. In: SILVA, Alcione Leite; LAGO, Mara Coelho de Souza; RAMOS, Tânia Regina Oliveira (Orgs.). Falas de Gênero. Santa Catarina: Editora Mulheres, 1999.

VIETTA, Katya; BRAND, Antonio. Missões evangélicas e Igrejas neopentecostais entre os Kaiowá e os Guarani em Mato Grosso do Sul. In: WRIGHT, Robin M. (Org.). Transformando os deuses: igrejas evangélicas, pentecostais e neopentecostais entre os povos indígenas no Brasil. Campinas, SP: Editora da Unicamp, 2004.

WAGNER, Roy. A invenção da cultura. DE SOUZA, Marcela Coelho e MORALES, Alexandre (trad.). São Paulo: COSAC NAIFY, 2010. 253 p. 